\title{
ظاهرة التسول في إندونيسيا ونظرة الإسلام فيه وعلاجه
}

Ibnu Hafid Alfarisy

$$
\begin{aligned}
& \text { طالب شعبة ماجستير تعليم اللغة العربية قسم الأدب العببي كلية الآداب } \\
& \text { جامعة مالانج الحكومية } \\
& \text { معلم مدرسة الإرشاد تينجاران المتوسطة الإسلامية السابعة مدينة باتو } \\
& \text { email: hafizh94elfarisy@gmail.com }
\end{aligned}
$$

المستخلص : التسول فعل مذموم عند الإسلام بل عند المجتمع. وهو طلب العطاء أو طلب الرحمة من شخص بطرق متنوعة. هدفت الدراسة الحالية إلى معرفة مفهوم التسول

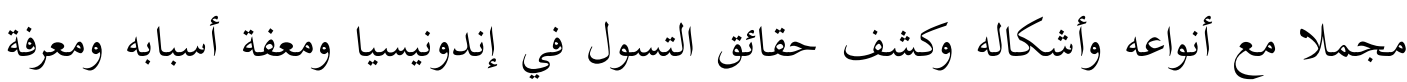
نظرة الإسلام فيه ووصف موقف الناس تجاهه ووصف علاجه. استنتجت الدراسة أن للتسول أنواعا منه ما هو لحاجة ومنه ما هو لخداع. بلغ عدد المتسولين في إندونيسيا

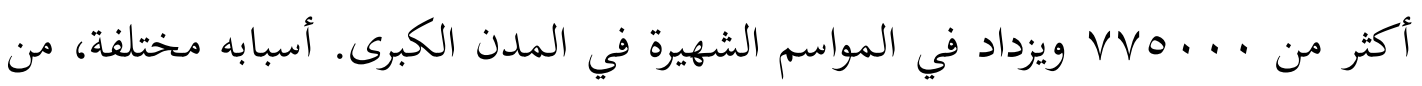

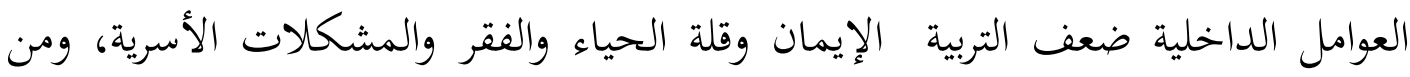

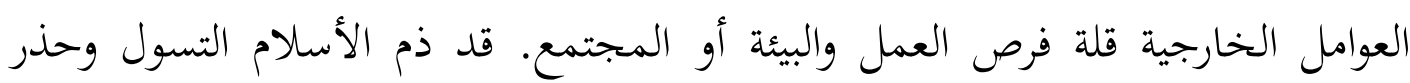
الناس منه بوعيد كثير شديد وحثهم على كسب اليد والصدقة. موقف الناس تجاه المتسلوين في الأصل أن يعطوهم دون النظر إلى أصليتهم. ومن العلاجات المقترحة لظاهرة التسول التربية الدينية و الاجتماعية الحسنة و تجهيز فرص العمل وهذا مسؤولية الحكومة وأفراد المجتمع معا.

كلمات المفتاح : ظاهرة التسول، إندونيسيا، نظرة الإسلام، العلاج 
المقدمة

إن التسول ظاهرة العالم لا معارضة فيها.كان التسول موجودا من قبل مجيء الإسالام. بل حتى يكون الأمر عنيفا. قد يقتل الأب ولده خشية إملاق. وبعد مجيء الإسلام برسالة النبي محمد صلى الله عليه وسلم بين أن الإسلام يذم التسول ويحث على كسب اليد و التصدق. من الأصناف الذين يحق لهم التسول هم من أصابته فاقة و من عليه دين كيثر ومن أصابت ماله جائحة. فليحذر كل واحد من التسول و هو ليس في حاجة أو قادر على كسب العيش.

هذه المقالة تتناول بعض الأمور المهمة عن التوسول وهي تعريف التسول وأنواعه وحقائق التسسول في إندونيسيا وأسباب التسول والتسول فس نظرة الإسلام وموقفنا تجاه المتسولين وعلاج ظاهرة التسول.

\section{تعربيف التسول و أنواعه}

التسول لغة أنه من فعل تسول وهو مشتق من سول معناه شحذ أو سأل

واستعطى. ولفظ التسول ليس اللفظ المأخوذ من القرآن و السنة. أما اللفظ الذي ورد فيهما المسألة من كلمة سأل. و لفظ التسول لفظ في هذا العصر الحديث. واستخدمت أيضا التشريعات ألفاظا أخر للتسول مثل الاستجداء والتكفف والتلمس

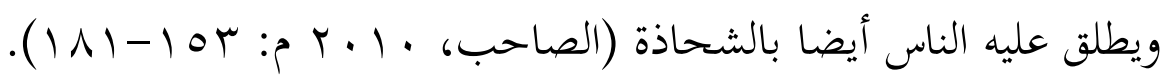

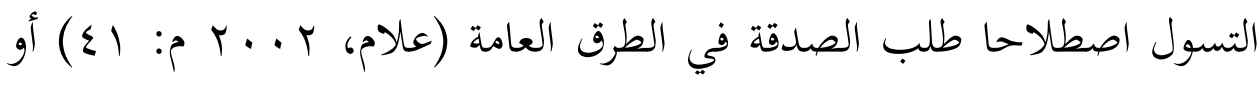

الاستعطاء وطلب الصدقة باستخدام وسائل مخلفة لنيل العطف والشفقة (عنبتاوي، ع . . ץ م: ب ب). فالمتسول من استعطى الناس الإحسان في الطرق العامة باستخدام وسائل مختلفة لنيل العطف والشفقة. 
ويمكن أن تصنف أنواع التسول من خلال الواقع و بالخاصة في المجمتمع

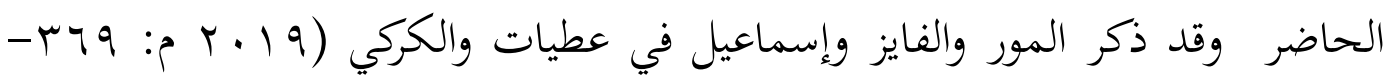

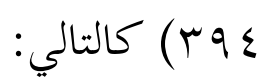
ا - تسول مباشر، يتسول المتسول بالظهور والصراحة.

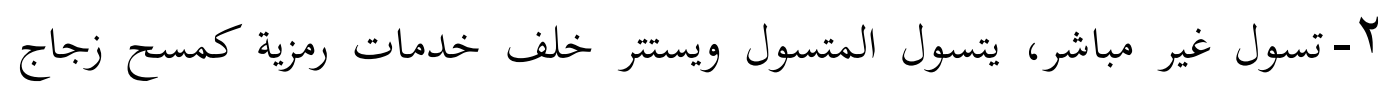
السيارة بدون طلب.

$$
\text { ع - - تسول إجباري، يتسول المتسول من إجبار أحد يستغله. }
$$

0- تسول موسمي، يتسول المتسول في احتفالات دينية أو وطنية أو أعياد. 7 - تسول طارئ، يكون المتسول مضطرا لحاجة ضرورية كشخص ضل طرول طريقه وضاع

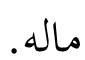

V- مسول الشخص القادر، يكون المتسول قادرا على الكسب و العمل.

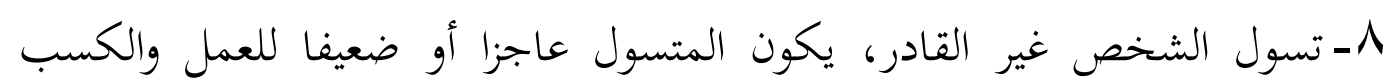
كصاحب الإعاقة. 9 - تسول الجانح، وهو التسول الذي تصحبه الجريمة كالسرقة. حقائق التسول في إندونيسيا وزير الشؤون الاجتماعية Agus Gumiwang Kartasasmita في يوم الخميس التاريخ r T أغسطس و 1 ـ ب قال إن عدد المتسولين في المدن الكبرى في إندونيسيا

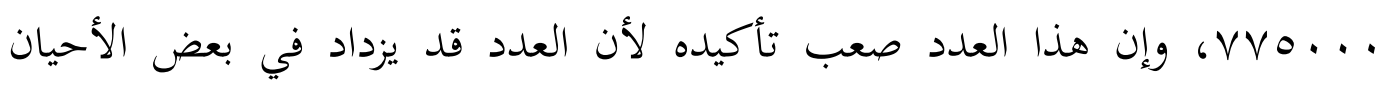
والمواسيم المعينة مثل العيد، وظن أن العدد الحقيقي أكبر مما في الإحصاء. لأن

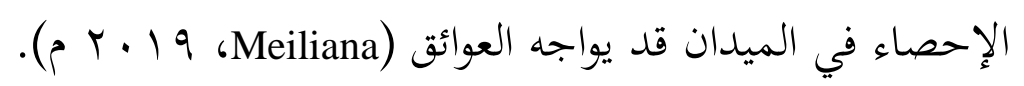
من المشاكل التي تدفع الناس للتسول هي ضيق الأراضي وضعف التربية عدم الترات

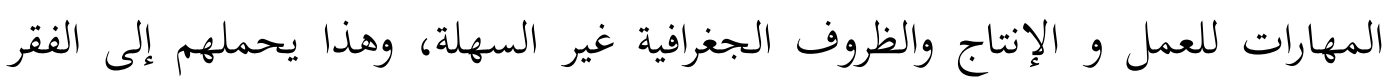


وإلى الطبقات الاجتماعية السفلى. وهم مضطرون إلى التسول في المدن وإشراك النساء

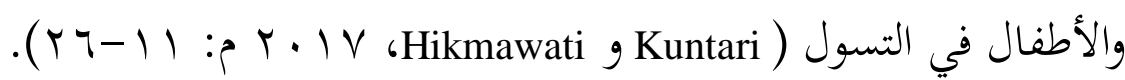

$$
\text { أسباب التسول }
$$

الأسباب التي تسبب ظهور التسول متنوعة، ووذكر شلهوب بعض أسباب

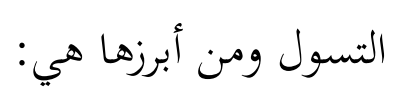

ا ـ التنشئة الاجتماعية الخاطئة مثل الإهمال والنقصان في الرعاية الاجتماعية.

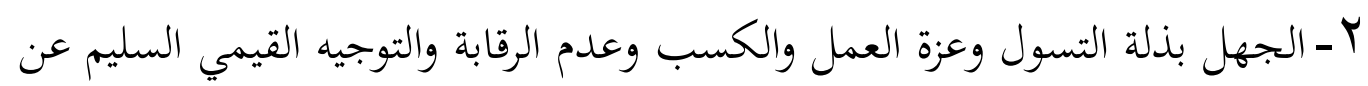

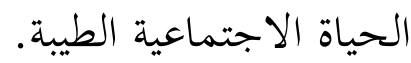

آ- مشكلات العمل مثل عدم التوافق بين فرص العمل المتاحة و بين التخصصات الموجودة. وعدم الكفاءة الكافية في مجال العلم يسبب عدم التحمل و الاستقرار

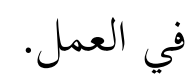

ع ـ الإدمان على المخدرات والكحول يؤدي إلى الكسب و العمل بطريقة غير لازمة. 0ـ الضعف الأخلاقي و إهمال الآباء لأولادهم.

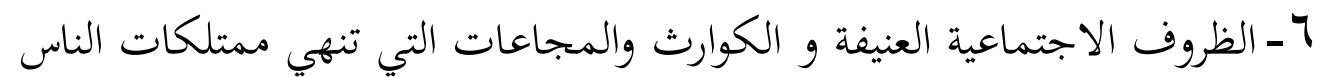

$$
\text { فيضطرون إلى التسول. }
$$

وأظهرت الدراسة أن تاريخ الأسرة من التسول، والإعاقة ، وموت الأب، وحجم العم

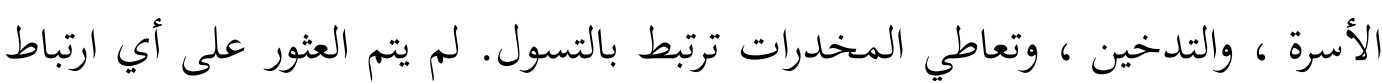

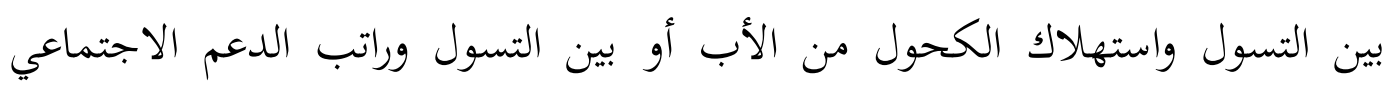

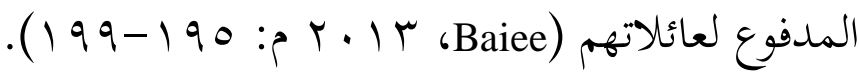

$$
\begin{aligned}
& \text { V - بيئة التسول. }
\end{aligned}
$$

1ـ الفقر والعوز الذي يؤدي إلى انخفاض الدخل و عدم القدر على استيفاء

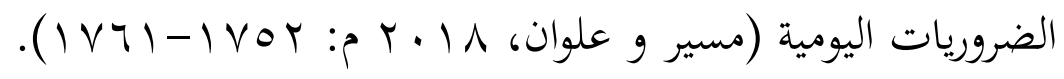




\section{التسول في نظرة الإسلام}

قد ذم الله تعالى و رسوله صلى الله عليه وسلم التسول حيث أنه ذلة وإهانة النفس للناس فالإسلام يحث على العزة والتعفف من الأفعال الرذيلة. وهناك بعض ولى

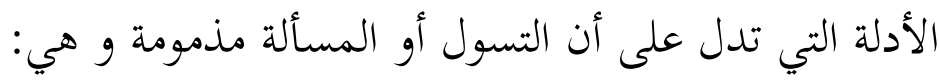
ا ـ الصورة القبيحة التي يجعل الله المتسول عليها في الحديث قال النبي صلى الله عليه وسلم: " من سأل الناس وله ما فالها

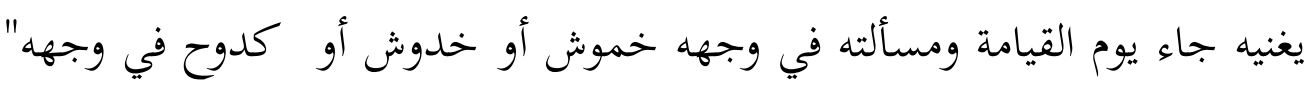

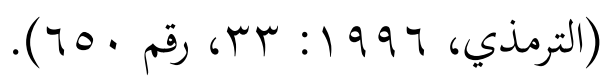

قال القاضي عياض في معنى هذا الحديث: " يأتي يوم القيامة ذليلاً

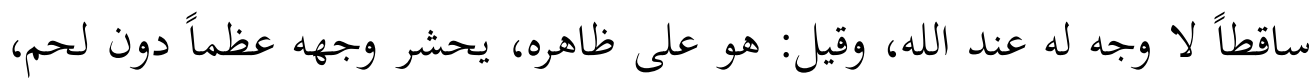

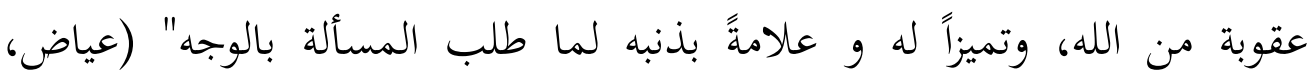

$$
\begin{aligned}
& \text {. } \\
& \text { ז - إعداد العذاب الشديد }
\end{aligned}
$$

وفي الحديث، عن أبي هريرة رضي الله عنه قال: قال الرسول صلى الله

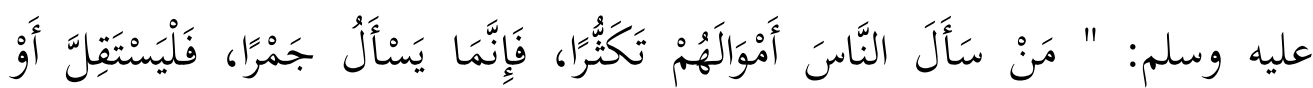

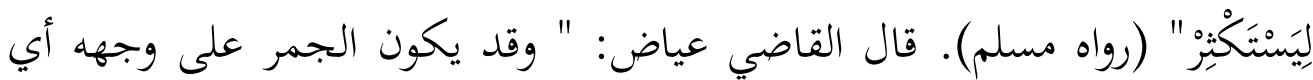

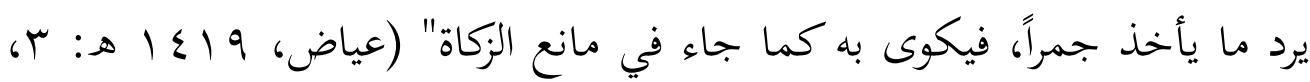

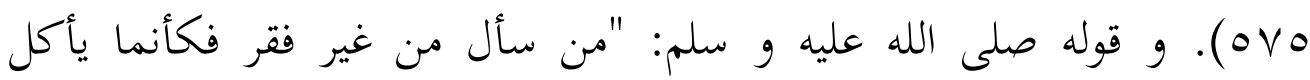

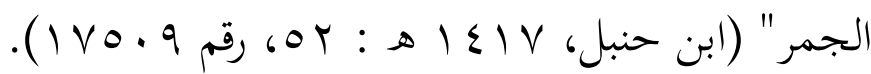

$$
\begin{aligned}
& \text { بـ تبديل حال المتسول من الغنى إلى الفقر. }
\end{aligned}
$$

ومن الأحاديث الموضحة لذلك قوله صلى الله عليه وسلم: " لَا يَفْتَحُ

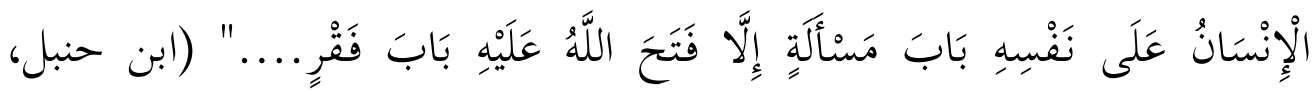

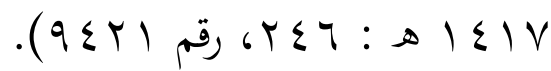




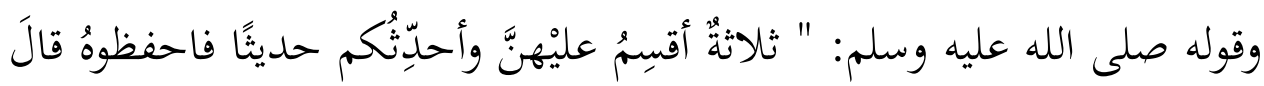

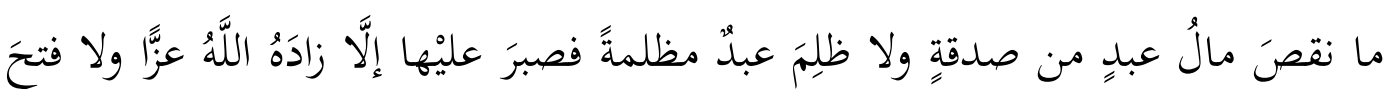

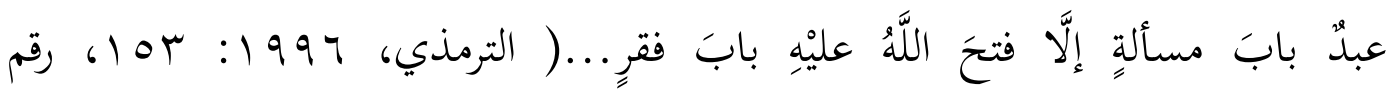
. (rTHO

فالمسألة عن ظهر الغنى عواقبها قبيحة ضارة، ولا يسلم صاحبها من الضيق والعنت وسوء الحال. وقد لخص الرسول صلى الله عليه وسلم بعبارة جامعة فقال: " لو

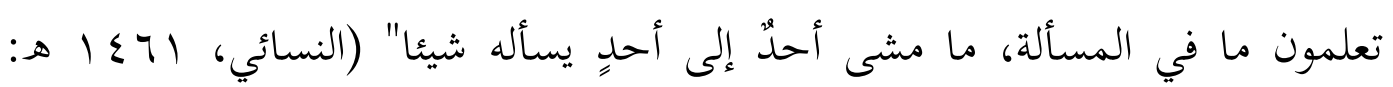

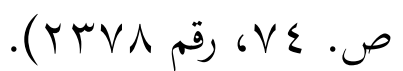

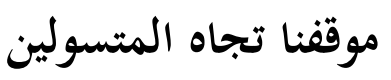

قد سئل الشيخ ابن باز رحمه الله عن إعطاء المتسولين أو منعطم. فأجاب بأن

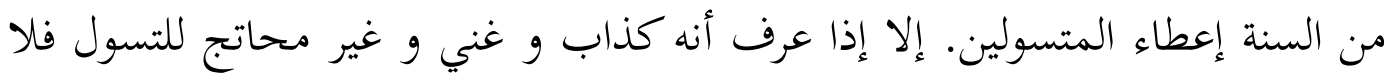
يعطى. ولكن إذا جهل حاله و بدا أنه محتاج و فقير فمن السنة أن يعطى. و و هذا إلها

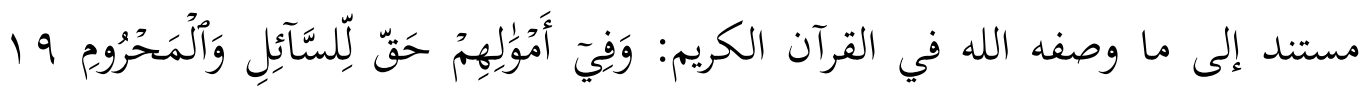

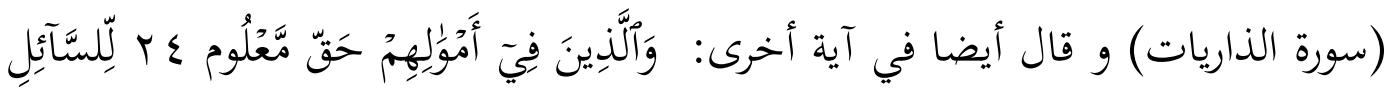

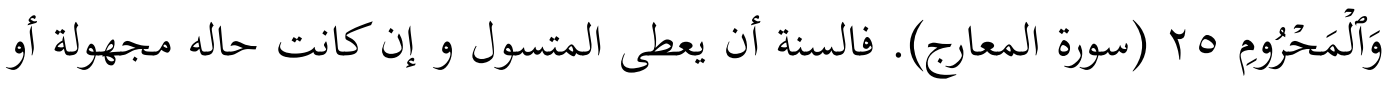

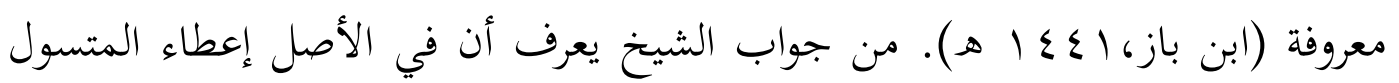
دون النظر إلى صدقه أو كذبه. علاج ظاهرة التسول

و يمكن أن تكون المعالجات للتسول من قبل الدين الأسلامي و الأفراد و

$$
\begin{aligned}
& \text { المجتمع و الحكومات كالآتي: } \\
& \text { I - غرس القيم و تصحيح المفاهيم } \\
& \text { أ) غرس القيم الحميدة }
\end{aligned}
$$

الإنسان لابد أن يعرف القيم المهمة لأن لا يتسول أو من أراد أن

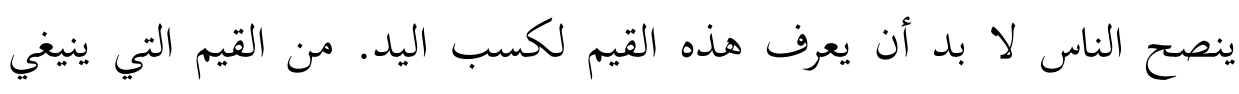


مراعاتها وفهمها لدى كل أحد هي القناعة والاستعفاف والاستغناء عن الخلق

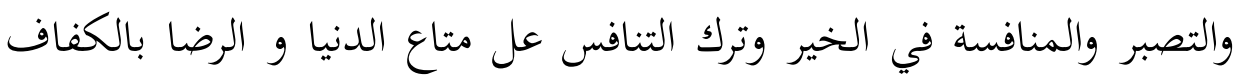
وتعظيم نعم الله والتقدير على العمل والحرص على الأكل من كسب اليد. ب) تصحيح المفاهيم

ومن المفاهيم التي ينبغي أن يفهمها الإنسان أو الناصح أن الغنى ليس النسم

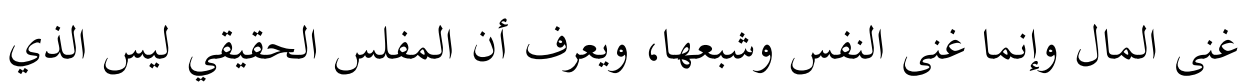

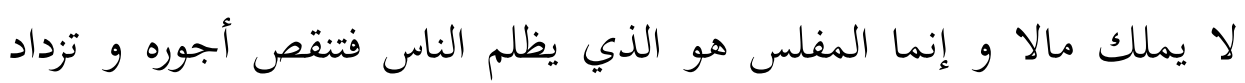
خطاياه يوم القيامة، ويعرف أيضا أن المسكين هو الذي ليس له غنى لهن يغنيه

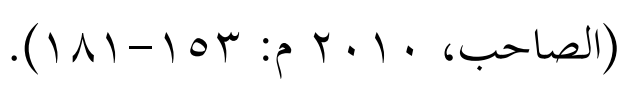$$
\text { Y - الترغيب في سؤال الله تعالى و ترك سؤال الناس ل }
$$

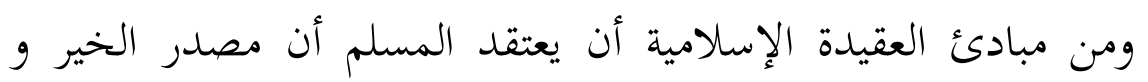

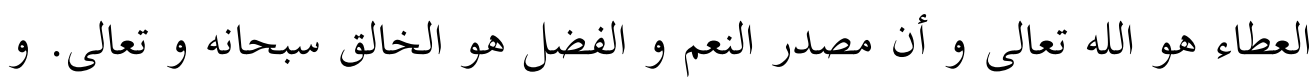

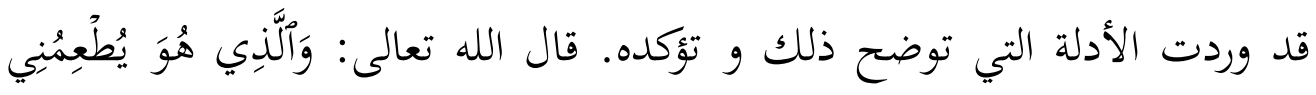

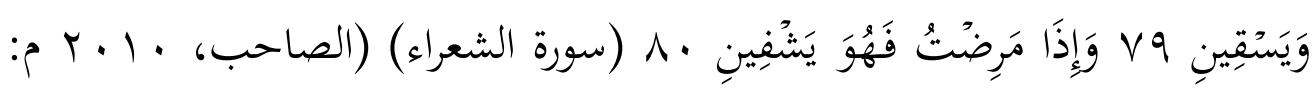

$$
\text { . (1) } 11-104
$$

وفي الحديث: عن أبي ذر الغفاري رضي الله عنه، عن النبي صلى الله

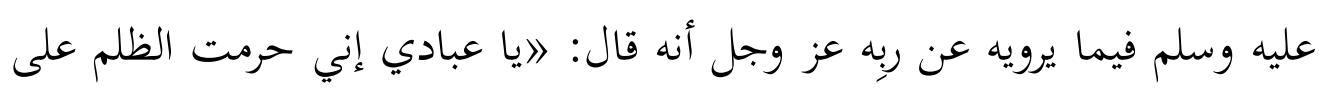

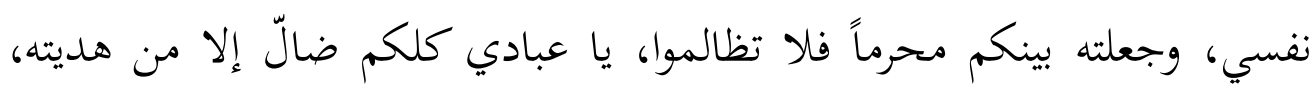

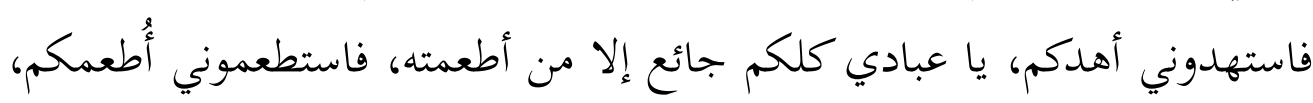

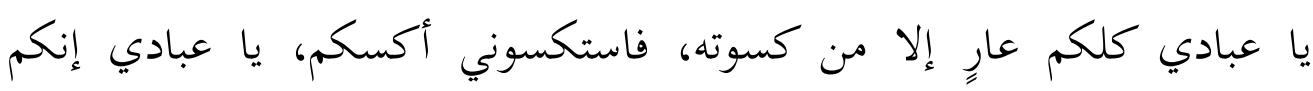
تخطئون بالليلِ والنهار، وأنا أغفر الذنوب جميعاً فاستغفروني أغفر لكم، يا عبادي إنكم لن تبلغوا ضري فتضروني، ولن تبلغوا نفعي فتنفعوني، يا عبادي لو أن أولكم

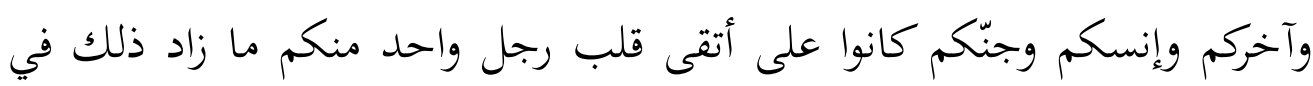

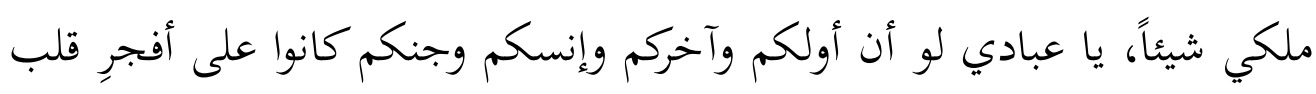


واحد منكم ما نقص من ملكي شيئاً، يا عبادي لو أن أولكم وآخركم وإنسكم

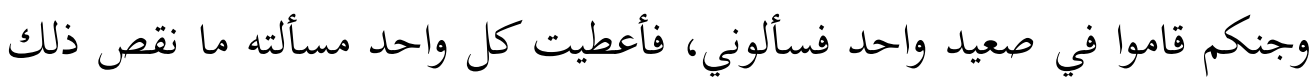

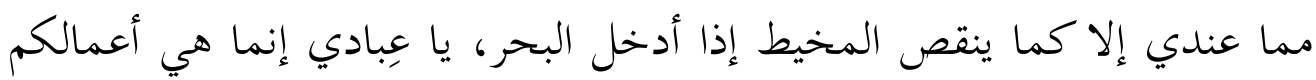

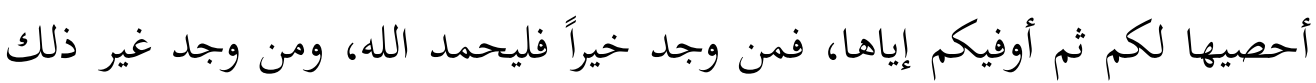

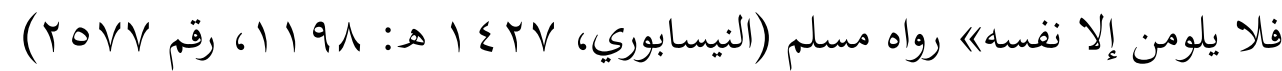

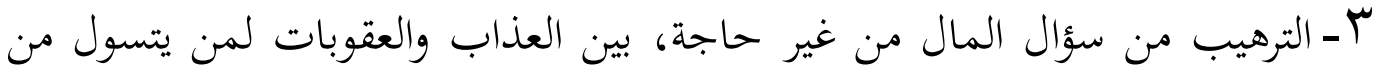
غير حاجة وهو قادر على العمل والكسب.

ع- توفير فرص العمل والهيئات لتأهيل وتزويد الناس المهارات المهنية، هذا من فئ مسؤولية الحكومة خصوصا والأفراد عموما. فكسب اليد خير عمل وإن كان وترئ خفيفا قليل الدخل. 0- بيان من تحق له المسألة، أن هناك أفرادا تحق لهم المسألة وهم المصاب بالفقر الشديد ليس له غنى يغنيه والمصاب بالكوارث كاحتراق البيت وزوال المزارع بسبب الحشرات وزوال البيت والمال بسبب الفيضان وصاحب الدين.

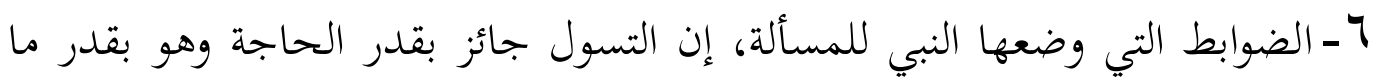

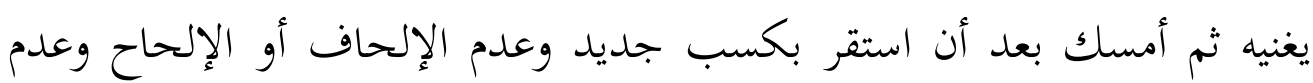

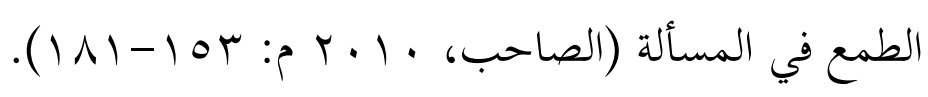

الخلاصة

إن التسول مذموم في نظرة الإسلام وهو يسيئ النظر في المجتمع لأنه يدل

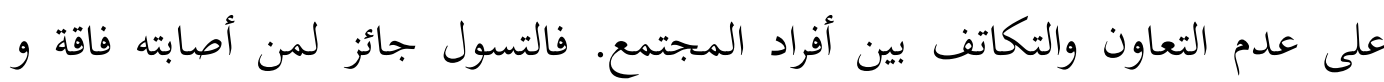
الدين و الجائحة وأما سوى ذلك مذموم. لأن الإسلام يحث على العمل وكسب اليد.

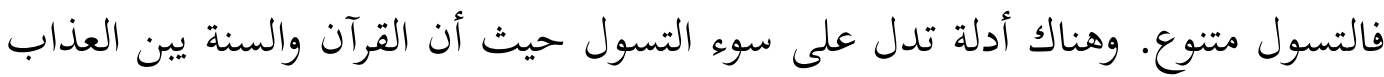
واللعنة يوم القيام للمتسولين من غير حاجة. ينبغي للإنسان أن يعرف أن التسول إهانة النفس للناس وعدم التوكل على الله. 
من البيات السابقة أن الإنسان لا يتسول إلا من أصحاب الحاجة الذين قد

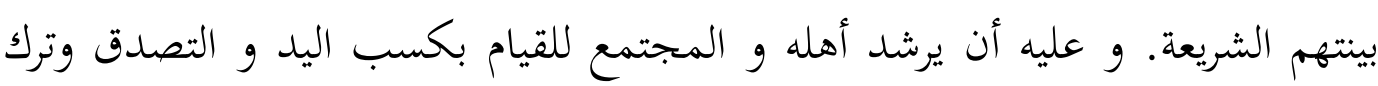

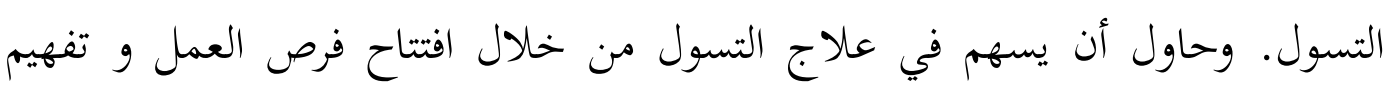
الناس عن آثار التسول تفهيما دينيا واجتماعيا. 


\section{المراجع}

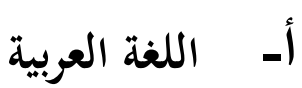

ابن باز. إع ا هـ. حكم إعطاء المتسولين. (عبر الإنترنت)، (ما-حكم-اعطاء-

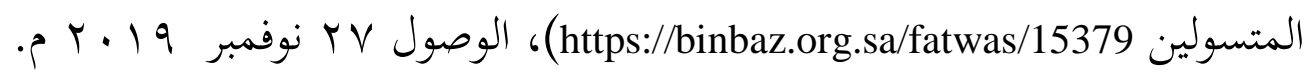

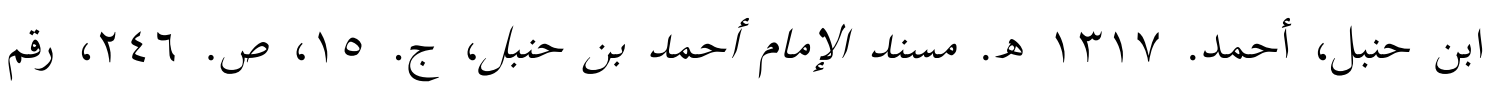

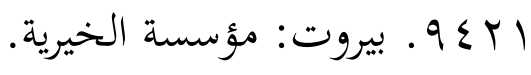

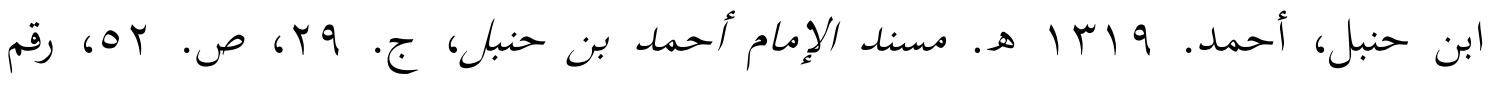

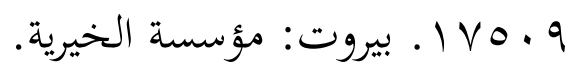

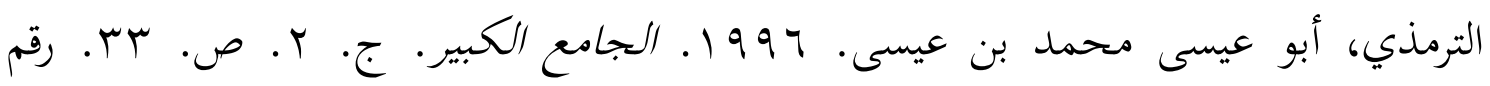
.

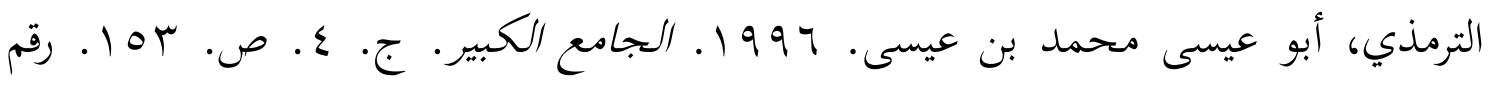
. عياض، القاضي. 9 إ 1 هـ. إكمال المعلم بنوائل مسلم. المنصورة: دار الوفاء. الصاحب، محمد عيد محمود. · · · م. المنهج النبوي في علاج التسول. المجلة

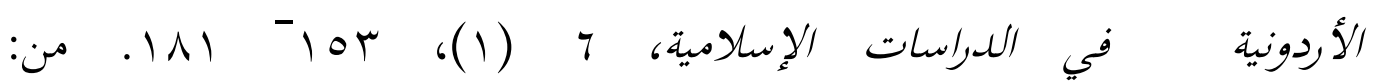
http://www.riyadhalelm.com/researches/14/5_tasawl.pdf

صحيح مسلم كتاب " :الزكاة "باب " :النهي عن المسألة " رقم الحديث: إـــ عطيات، فاطمة أحمد و نسرين محمود الكركي. 9 ا.ب م. استخدام الأطفال في التسول في المحتمع الأردني: دراسة إثنوغرافية. مجلة الجامعة الإسلامية للبحوث الإنسانية، من

http://journals.iugaza.edu.ps/index.php/IUGJHR/article/view/3469 


$$
\begin{aligned}
& \text { علام، ابتسام. r . . r م. الجماعات الهامشية - دراسة أنثروبولوجية لجماعات } \\
& \text { المتسولين بملينة القاهرة. القاهرة: مركز البحوث و الدراسات الاجتماعية كلسة } \\
& \text { الآداب جامعة القاهرة. } \\
& \text { منشورة، أيار : قسم علم الاجتماع بالجامعة الأردنية. }
\end{aligned}
$$

مسير، لقاء عبد الهادي و أمل عبد الحسن علوان. 11 . ب م. ظاهرة التسول و علاقته بالانحراف الاجتماعي لدى الفتيات في المجتمع العراقي. مجلة كلية التببية الأساسية

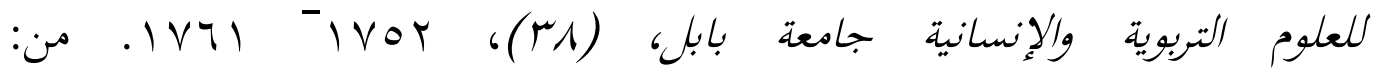
https://www.iasj.net/iasj?func=article $\&$ aId=142761

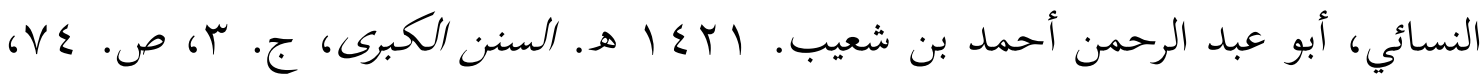

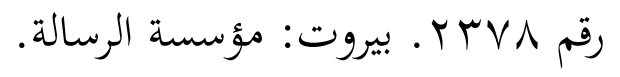

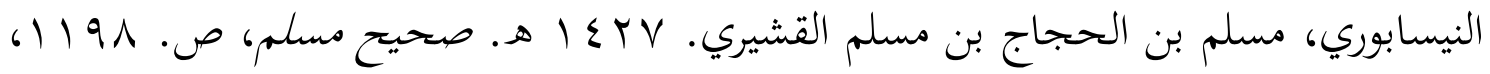
رقم roVV. مصر: دار طيبة.

\section{اللغة الأندونيسية و الإنجليزية}

Baiee, Hasan Alwan Hussien. 2013. Factors Contributing to Child Begging in Hilla City- Babylon- Iraq during the Year 2011. Iraqi Journal of Community

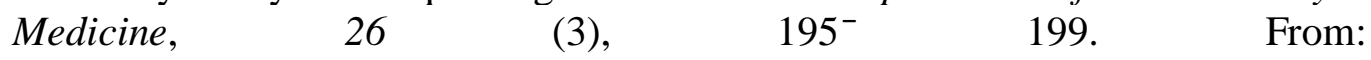
https://www.iasj.net/iasj?func=article \&aId=76343

Kuntari, sri dan Eny Hikmawati. 2017. Melacak Akar Permasalahan Gelandangan Pengemis (Gepeng). Media Informasi Penelitian Kesejahteraan Sosial, 41 (1), $11^{-}$26. DOI: $\quad$ https://doi.org/10.31105/mipks.v41i1.1192

Meiliana, Diamanty. 2019. Diperkirakan Ada 77.500 Gepeng di Kota- $\quad$ kota Besar di Indonesia, (Online), (https://nasional.kompas.com/read/2019/08/22/21281421/diperkirakan-ada77500-gepeng-di-kota-kota-besar-di-indonesia), diakses 4 Desesmber 2019. 
